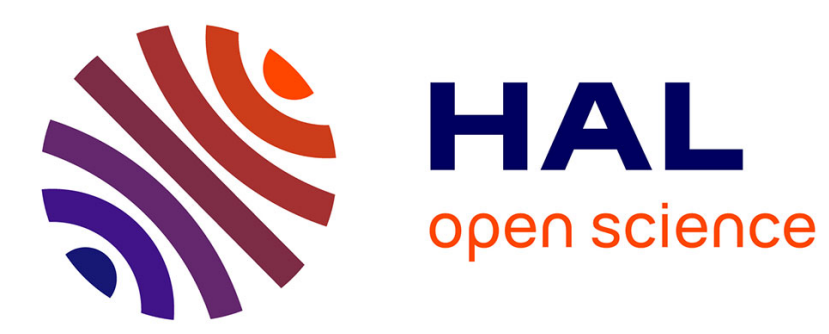

\title{
High Efficiency White Luminescence of Alumina doped $\mathrm{ZnO}$
}

\author{
Alban A. Letailleur, Sergey Yu Grachev, Etienne Barthel, Elin Sondergard, \\ Komla Nomenyo, Christophe Couteau, Stefan Mc Murtry, Gilles Lerondel, \\ Emilie Charlet, Emmanuelle Peter
}

\section{To cite this version:}

Alban A. Letailleur, Sergey Yu Grachev, Etienne Barthel, Elin Sondergard, Komla Nomenyo, et al.. High Efficiency White Luminescence of Alumina doped ZnO. Journal of Luminescence, 2011, 131 (12), pp.2646-2651. 10.1016/j.jlumin.2011.06.044 . hal-00602889

\section{HAL Id: hal-00602889 https://hal.science/hal-00602889}

Submitted on 23 Jun 2011

HAL is a multi-disciplinary open access archive for the deposit and dissemination of scientific research documents, whether they are published or not. The documents may come from teaching and research institutions in France or abroad, or from public or private research centers.
L'archive ouverte pluridisciplinaire HAL, est destinée au dépôt et à la diffusion de documents scientifiques de niveau recherche, publiés ou non, émanant des établissements d'enseignement et de recherche français ou étrangers, des laboratoires publics ou privés. 


\title{
High Efficiency White Luminescence of Alumina doped $\mathrm{ZnO}$
}

Alban A. Letailleur, ${ }^{1,2,3,}{ }^{*}$ Sergey Yu Grachev, ${ }^{1}$ Etienne Barthel, ${ }^{1}$ Elin Søndergård ${ }^{1}$, Komla Nomenyo, ${ }^{2}$ Christophe Couteau, ${ }^{2}$ Stefan Mc Murtry, ${ }^{2}$ Gilles Lérondel, ${ }^{2}$ Emilie Charlet, ${ }^{4}$ Emmanuelle Peter ${ }^{4}$

${ }^{1}$ Surface du Verre et Interfaces, UMR 125 CNRS/Saint-Gobain, 39 quai Lucien Lefranc, BP 135, 93303 Aubervilliers Cedex, France

${ }^{2}$ Laboratoire de Nanotechnologie et d'Instrumentation Optique, Institut Charles Delaunay, CNRS UMR 6279, Université de Technologie de Troyes, 12 rue Marie Curie, BP 2060, 10010 Troyes Cedex, France

${ }^{3}$ Laboratoire de Chimie de la Matière Condensée de Paris, UMR CNRS 7574, UPMCUniversité Paris VI, Collège de France, 11 place Marcelin Berthelot, 75231 Paris, France

${ }^{4}$ Thin Films Division, Saint-Gobain Recherche, 39 quai Lucien Lefranc, BP 135, 93303 Aubervilliers Cedex, France

*alban.letailleur@saint-gobain.com,tel:+3314839 59 56,fax: + 33148395562

\begin{abstract}
The application of Alumina-doped $\mathrm{ZnO}(\mathrm{AZO})$ films as luminescent material for large area lighting sources has been evaluated. Thin films were grown on quartz using magnetron sputtering and subsequently annealed under argon atmosphere in a rapid thermal annealing experiment. Below $550{ }^{\circ} \mathrm{C}$, red-shift of the optical band gap and increase of the visible emission are observed in agreement with $\mathrm{Al}$ diffusion and formation of interstitial oxygen atoms. At temperatures higher than $800{ }^{\circ} \mathrm{C}$, diffusion is activated and Ostwald ripening leads to the formation of larger grains and an increase of the crystalline phase. The photoluminescence (PL) intensity is enhanced, specifically in the UV range. As a result the emission spectrum of AZO thin films can be adjusted by the annealing conditions, with equal
\end{abstract}


contributions from the UV and orange parts of the PL spectrum resulting in an efficient white emission as quantified using the color space map of the Commission Internationale de l’Éclairage.

Keywords: Zinc oxide; doping; white luminescence; rapid annealing

\section{Introduction}

Zinc oxide $(\mathrm{ZnO})$ is an abundant and non toxic oxide which has been widely used as catalyst, sun screen or for medical applications. ${ }^{1}$ A more recent interest focuses on the optoelectronic properties of $\mathrm{ZnO}$. With a direct band gap of $3.37 \mathrm{eV}$ and an exciton binding energy of 60 $\mathrm{meV}, \mathrm{ZnO}$ is a promising candidate for room temperature ultraviolet optoelectronic devices, such as light emitting diodes. ${ }^{2}$

The luminescence of $\mathrm{ZnO}$ presents a wide variety of emission lines, with strong dependence to structural details. Photoluminescence (PL) spectra are usually separated in two contributions: a UV-peak around $380 \mathrm{~nm}$ and a visible contribution. Whereas the UV line is associated with the exciton recombination, the exact origin of the visible luminescence is still controversial. ${ }^{3}$ Defects inside the material act as strong recombination centers and emission bands are generated by donor-acceptor pair transitions. Those defects can be oxygen or zinc vacancies or interstitial atoms, or even pollutants. ${ }^{4}$

A large variety of $\mathrm{n}$-dopants can be incorporated inside the $\mathrm{ZnO}$ to increase the range of applications from spintronics, ${ }^{5}$ ferroelectric layers, ${ }^{6}$ or transparent conductive oxide. ${ }^{7}$ Doping or co-doping the layer (with elements from the groups I, IIIb or V) modifies the energy levels and is also widely used to adjust the luminescence properties of $\mathrm{ZnO}$ thin films, by either shifting or broadening the several emission peak. ${ }^{8} \mathrm{Al}$ doping leads particularly to a yellow luminescence, ${ }^{9}$ whereas Li doping is used to adjust the peak position and its intensity. ${ }^{10}$ Co- 
doping of these elements therefore leads to a broad-band yellow-white emission. ${ }^{11}$ Obtaining a white luminescence with Alumina-doped $\mathrm{ZnO}(\mathrm{AZO})$ is therefore a challenge.

There is an emergent need for large lighting sources. To obtain AZO thin films on large areas and achieve a precise control over the doping, solution-based processing (like the sol-gel method) is widely used. ${ }^{12,13}$ However, the large solvent content inside the material leads to porosity and reduces coating life-time. Along the physical method used for the AZO deposition, magnetron sputtering emerges as an easy way to coat surfaces at the window scale. The versatility of this method enables the deposition on various substrates such as sapphire, ${ }^{14}$ silicon, ${ }^{15}$ or glass. ${ }^{16}$

To improve the coating properties after deposition, samples are subsequently annealed. Control over the annealing atmosphere is of great importance to obtain the desired properties. Annealing in air or oxygen generally leads to a strong increase of the visible luminescence and a reduction of the UV peak. ${ }^{17,18}$ This can subsequently be recovered by annealing the sample under reducing atmosphere. ${ }^{19}$ Furthermore, annealing in vacuum or under nitrogen leads to a specific increase of the UV part of the spectrum. ${ }^{20}$

In applications, fast annealing is a requisite. In this work, we have probed the impact of Rapid Thermal Annealing on the luminescence of AZO thin films on quartz. The films were annealed during five minutes under argon atmosphere at temperatures up to $950{ }^{\circ} \mathrm{C}$. The structural and optical properties of the obtained films were investigated. Impact on the luminescence was determined. In particular we show that white luminescence can be obtained in specific conditions.

\section{Materials and Methods}

The AZO films were grown on quartz substrates (synthetic quartz, Shin-Etsu, Japan) by RF magnetron sputtering from an AZO target (GfE Fremat, Germany). Quartz was chosen as 
substrate because of its high transparency in the visible and UV ranges and for its chemical stability. The doping amount of $\mathrm{Al}_{2} \mathrm{O}_{3}$ in the $\mathrm{AZO}$ target ranged between 1 and 4 weight percent.

Quartz wafers $\left(10 \times 10 \mathrm{~cm}^{2}\right)$ were used as received and placed onto a $30 \times 30 \mathrm{~cm}^{2}$ glass plate into the sputtering chamber. The chamber was evacuated to $10^{-6}$ mbar. Argon was introduced through a mass flow controller and the working pressure was maintained to $8-10 \cdot 10^{-3}$ mbar. The input power was kept at $2000 \mathrm{~W}$. The substrates are in translation under the AZO target and the growth rate is $30 \mathrm{~nm} \cdot \mathrm{m}^{-1} \cdot \mathrm{min}^{-1}$.

The thickness of the films was $750 \mathrm{~nm}$ as measured with a surface profilometer (DEKTAK 3, USA) and Scanning Electron Microscopy (SEM, LEO DSM 982 Gemini).

The AZO samples were subsequently cut into pieces of $2 \times 2 \mathrm{~cm}^{2}$ and placed into the annealing oven. The chamber was flushed with argon during $10 \mathrm{~min}$ prior to annealing, and the gas flow $(50 \mathrm{sccm})$ was maintained during annealing. The heating time was set to $10 \mathrm{~s}$ and the cooling rate was about $5 \mathrm{~K} \cdot \mathrm{s}^{-1}$. Samples were annealed at different temperatures $\mathrm{T}_{\mathrm{a}}$ (between $350{ }^{\circ} \mathrm{C}$ and $950{ }^{\circ} \mathrm{C}$ ) for various times $\mathrm{t}_{\mathrm{a}}$ (between $15 \mathrm{~s}$ and $300 \mathrm{~s}$ ).

X-Ray diffraction (XRD) film patterns were obtained with a PHILIPS PW1830 diffractometer $(\theta-2 \theta$ Bragg-Brentano geometry) operating with $\mathrm{Cu} \mathrm{K} \alpha$ radiation $(\lambda=1.5418 \AA)$ and equipped with a graphite back monochromator.

Optical transmissions of the films were measured under normal incidence by a UV-VIS spectrophotometer between 350 and $800 \mathrm{~nm}$. Photoluminescence (PL) spectra were collected at room temperature under normal incidence using a $50 \mathrm{~cm}$ focal length spectrometer with a $300 \mathrm{gr} / \mathrm{mm}$ grating, coupled to a Peltier-cooled CCD camera. Samples were excited at an incidence angle of $50^{\circ}$ using a $325 \mathrm{~nm} \mathrm{He}-\mathrm{Cd}$ laser with an output power of $5 \mathrm{~mW}$. The laser beam was focused to $100 \mu \mathrm{m}$ with a $35 \mathrm{~mm}$ aspherical lens. The presented spectra were corrected by the spectral responses of the measurement set-up. 


\section{Results and discussion}

\subsection{Effect of annealing temperature on the structural properties}

Figure 1 a-d presents top views of the surface of the AZO films obtained by SEM, before (a) and after thermal annealing during $300 \mathrm{~s}$ at $\mathrm{T}_{\mathrm{a}}=650{ }^{\circ} \mathrm{C}(\mathrm{b}), 800^{\circ} \mathrm{C}(\mathrm{c})$, and $900{ }^{\circ} \mathrm{C}(\mathrm{d})$. The asdeposited film is well crystallized with an average grain size of $40 \mathrm{~nm}$. Figure 1e presents a side view of the as-deposited film. The film is about $750 \mathrm{~nm}$ thick and presents a columnar structure with a lateral size of the columns of the order of $40 \mathrm{~nm}$, which is consistent with the top view. ${ }^{21}$ The columns are not perfectly straight because the substrate is moving under the target in the magnetron chamber during the sputtering deposition. At the beginning of the sputtering, the substrate is not under the target and the flux of atoms arrives at the surface under an angle, which results in the tilt of the columns. Upon translation, the substrate arrived right under the target, and no angle is observed. Finally, when the sample is far away from the target a tilt in the other direction is observed. Thermal annealing at temperatures lower than $750{ }^{\circ} \mathrm{C}$ does not induce modifications of the surface morphology and grain size (Fig. 1b). At $800^{\circ} \mathrm{C}$, the grains start growing and an average grain size of 60 and $100 \mathrm{~nm}$ is observed after thermal annealing at $800{ }^{\circ} \mathrm{C}$ and $900{ }^{\circ} \mathrm{C}$ respectively. Moreover, the geometry of the grain is also affected by the annealing and a faceting of the grains is observed, with the formation of a $120^{\circ}$ angle at the boundary between three grains (shown on Figure 1d). This increase of the grain size and the modifications in the grain morphology may be induced by Ostwald ripening; zinc oxide diffusion becomes significant at temperatures higher than $800^{\circ} \mathrm{C}$ and allows for the formation of larger grains. ${ }^{22}$

The crystalline structure of the samples was further investigated by X-ray diffraction (XRD). Figure 2a presents the diffraction patterns of the films before and after annealing at $950{ }^{\circ} \mathrm{C}$. The diffraction patterns are dominated by a peak at around $34.5^{\circ}$ and a smaller one at 
$74^{\circ}$. These peaks are respectively assigned to the [002] and [004] orientations, ${ }^{23}$ demonstrating the marked texture of the film along the c-axis of the hexagonal structure in complete agreement with the columnar structure observed by SEM. The inset on Fig. 2a shows the position of the [002] peak after annealing at various temperatures for $t_{a}=300 \mathrm{~s}$. A progressive shift to higher $2 \theta$ value is observed even at relative low temperatures. It has been previously shown that, after the deposition, the AZO layers are in slight compression. ${ }^{24}$ This initial compressive stress along with the compressive thermal stress is relaxed during annealing, due to the formation of a larger crystalline phase. After full thermal treatment the residual stress is tensile, resulting in the shift shown on Fig. $2 a^{25}$

Another evidence of the modification of the crystalline structure is obtained from the shape of the XRD peaks. Figure $2 \mathrm{~b}$ presents the peak area and the full-width at half-maximum (FWHM) for the [002] peak after annealing at various temperatures. As $\mathrm{T}_{\mathrm{a}}$ increases, the FWHM decreases, reflecting an increase in the grain size. ${ }^{26}$ Very little variations are observed for $\mathrm{T}_{\mathrm{a}}<750{ }^{\circ} \mathrm{C}$, while the grain size increases significantly above $800{ }^{\circ} \mathrm{C}$, as previously demonstrated on Fig 1. On the other hand, At $800^{\circ} \mathrm{C}$ (resp. $900{ }^{\circ} \mathrm{C}$ ), the peak intensity increases by $25 \%$ (resp. $60 \%$ ). This shows the formation of a larger crystalline phase inside the materials.

\subsection{Effect of annealing temperatures on the optical properties}

The electronic properties of the $\mathrm{ZnO}$ samples can be derived from the optical transmission spectrum. The gap energy can be measured using the following formula: ${ }^{27}$

$$
A h v=C \cdot\left(E_{g}-h v\right)^{1 / 2}
$$

where $\alpha$ is the absorption coefficient of the sample, $h$ the Planck constant, $v$ is the frequency of the incident light, $E_{g}$ the gap energy and $C$ a constant. Figure 3 presents the 
evolution of $(\alpha h v)^{2}$ as a function of the photon energy $h v$. For the as deposited sample, the absorption is not sharp and the gap energy is $3.42 \mathrm{eV}$. After thermal annealing at $350{ }^{\circ} \mathrm{C}$, the gap increases to $3.54 \mathrm{eV}$. For thermal annealing at higher temperatures, the gap progressively shifts to lower values to finally reach $E_{g}=3.27 \mathrm{eV}$. A first possible explanation is a MossBurnstein shift due to the progressive reduction of the charge carrier density inside the material with the thermal annealing. In the initial state, the presence of electron donors leads to an increase of the optical gap: as the first levels of the conduction band are already filled, electrons from the valence band need more energy to reach the first unoccupied levels in the conduction band. ${ }^{28}$ Upon annealing at $350{ }^{\circ} \mathrm{C}$, the Al-dopants are activated leading to a slight blue shift of the optical band gap. This effect has already been observed for magnetron sputtered AZO thin films and is consistent with an increase in the film electrical conductivity. ${ }^{29}$

During annealing at temperatures higher than $450{ }^{\circ} \mathrm{C}$, the charge density decreases; this empties the lower levels of the conduction band and could explain the reduction of the absorption edge energy. To further study the origin of the absorption edge shift, the sample annealed at $950{ }^{\circ} \mathrm{C}$ under Argon was further annealed at $450{ }^{\circ} \mathrm{C}$ for one hour but under hydrogen. Hydrogen is known as reductant and leads to an increase of the charge carrier density. ${ }^{19}$ Figure 4 presents $(\alpha h v)^{2}$ as a function of the photon energy for the sample annealed under Argon and the one subsequently annealed under $\mathrm{H}_{2}$. A very small shift of the absorption band edge of $10 \mathrm{meV}$ is observed after the reductive treatment. This shift is more in agreement with the values commonly found for semiconductor doping. ${ }^{13}$ Therefore, the MossBurnstein shift is not the main reason of the modification of the absorbance spectra above 450 ${ }^{\circ} \mathrm{C}$.

Recent XANES studies suggest another explanation for the absorption modifications. Increasing the substrate temperature for magnetron sputtering AZO films leads to the 
formation of secondary phases of insulating $\mathrm{ZnO}$ and $\mathrm{ZnAl}_{2} \mathrm{O}_{4}$ from $\mathrm{Al}_{2} \mathrm{O}_{3}(\mathrm{ZnO})_{3}$ homologous phase. ${ }^{30-31}$ In our experiments, annealing at $450{ }^{\circ} \mathrm{C}$ and above, gives enough energy at the $\mathrm{Al}$ atoms to allow for diffusion and therefore segregation. The Al segregation leads to a different material and so to another band structure. This explains why a very large red-shift of the absorption edge is observed with a final value closed to the optical band gap of pure $\mathrm{ZnO}$.

Annealing also affects the shape of the absorption edge. For annealing above $800{ }^{\circ} \mathrm{C}$, a transition in the absorption edge is observed with a higher slope and a shoulder in the absorption around $3.32 \mathrm{eV}$. This shoulder may be assigned to the first exciton of $\mathrm{ZnO}{ }^{2}$ Finally, the position of the gap in the near UV associated with the sharp absorption edge leads to a high transmission of the sample. After thermal annealing, even at low temperatures, the optical transmission can reach $82 \%$. The overall transmission is limited by the reflection at the air/AZO interface due to the high index of AZO.

\subsection{Photoluminescence properties of AZO samples}

Figure 5 presents the photoluminescence (PL) spectra of the samples after annealing at various temperatures. The spectra were plotted in a log-scale to emphasize the strong increase of the PL intensity with thermal annealing. All the spectra present the two main luminescence contributions: the near band edge emission around 360-400 nm and the "orange emission" between 450 and $650 \mathrm{~nm}$. The overall intensity, the ratio between these two contributions, and the shape of the peaks show a strong dependence on $\mathrm{T}_{\mathrm{a}}$. Before annealing (black curve), the AZO sample presents a very weak luminescence and the signal is in the UV range. When the annealing temperature is increased, the near band edge emission increases and is progressively shifted to higher energy. Due to the increase of the grain size after annealing, 
the chances of non-radiative recombination are reduced and the PL signal is increased. Above $650{ }^{\circ} \mathrm{C}$, the near band edge emission presents two peaks at 380 and $390 \mathrm{~nm}$. This type of splitting was already reported for the study of room temperature cathodoluminescence of $\mathrm{ZnO}$ thin films. ${ }^{32}$ Actually, this is not a real splitting. The double peak structure can be simply explained by Fabry-Perot fringes. ' Indeed, this can be further evidenced at lower energy where the oscillations of the transmission spectra correspond to the modulation of the PL signal. To confirm this effect we simulated the luminescence by simply multiplying the transmission spectrum with two Gaussian peaks, one for the near band edge emission at 375 $\mathrm{nm}$ and the other to account for defect emission centered at $590 \mathrm{~nm}$. The result is shown on Figure 6. Dashed lines correspond to local maxima and illustrate the very good agreement between the experimental data and the simulated spectrum.

For annealing temperatures greater than $800{ }^{\circ} \mathrm{C}$, a strong increase of the overall intensity and more specifically the near band edge emission is observed. After annealing at $800{ }^{\circ} \mathrm{C}$ and $900{ }^{\circ} \mathrm{C}$, the intensity of the near band edge emission is respectively 8 and 80 times higher than after annealing at $750{ }^{\circ} \mathrm{C}$. The increase of the grain size observed previously with SEM and XRD explains the strong increase of the near band edge emission. For larger grains, the chance of a non-radiative recombination of the exciton on defect at the grain boundary is reduced and therefore the PL signal is increased.

Furthermore, the orange emission strongly increases with $\mathrm{T}_{\mathrm{a}}$ and indicates the creation of interstitial oxygen. ${ }^{33}$ This observation is a further evidence of the atom diffusion and phase segregation inside the materials. To heal the defects created by the phase segregation and control the ratio orange/visible emission, subsequent annealing into $\mathrm{H}_{2}$ atmosphere was performed. The reductive annealing leads to an increase of the ratio UV emission vs. visible emission of a factor 5 . 
The emission color was measured according to the standards of the Commission Internationale de l'Eclairage, (CIE) as defined in $1931 .^{34}$ The tristimulus values $\mathrm{X}, \mathrm{Y}$, and Z were obtained by convolving the emission spectra with the three Standard Colorimetric Observers. The chromaticity of the sample annealed at $950{ }^{\circ} \mathrm{C}$ were $\mathrm{x}=0.383$ and $\mathrm{y}=0.437$. These values are reported on the Figure 7. Clearly, the luminescence of the sample is set in the white region and is less orange than previously reported values for doped $\mathrm{ZnO}$ films. ${ }^{8}$ To further characterize this white emission, the corresponding color temperature was calculated from the $\mathrm{x}$, and $\mathrm{y}$ values and was found equal to $4500 \mathrm{~K}$. This is significantly higher than incandescent light bulb values, meaning a cooler light with a less yellowish contribution. The presence of a broad and significant near band edge emission around $390 \mathrm{~nm}$ explains why such a high value is found for the color temperature.

\subsection{Investigation of the Al segregation at $550^{\circ} \mathrm{C}$}

The Al segregation at low temperature can be further investigated by varying the annealing time to follow the kinetics. Samples were annealed at $550^{\circ} \mathrm{C}$ for various times ranging from 15 to $300 \mathrm{~s}$. Annealing at $550^{\circ} \mathrm{C}$ seems to be a good compromise between the need of a rapid annealing and a sufficiently slow kinetics to observe the variations. Figure 8 presents the FWHM and the position of the [002] peak in XRD experiments on the AZO thin films after annealing at $550{ }^{\circ} \mathrm{C}$. The [002] peak shifts to higher $2-\theta$ value even for very short annealing time and shows little increase for longer annealing. Even for short $t_{a}$, the residual compressive stress after deposition can relax easily during the annealing and the beginning of the cooling phase. After cooling, this leads to a final tensile stress and a shift of the XRD peak. The FWHM shows little decrease during the annealing; this evidences the limited impact of annealing at low temperature on the crystalline structure of the films. 
Figure 9 shows the evolution of the optical band gap, measured from the absorption of the sample (see Fig. 3). The same progressive reduction of the band gap due to the partial Al segregation of the films is observed. The values of the normalized visible emission, defined as the ratio of the "orange emission" to the near band edge UV emission; is also reported in Figure 9. This normalized visible emission increases strongly during annealing. To better understand the link between the PL spectrum and the optical properties, the normalized visible emission is given on Figure 10 as a function of the gap energy. The results confirm the crucial role of phase segregation in the optical and luminescence properties of the AZO thin films and demonstrate how a fine control over the annealing conditions enables the tuning of the emission properties.

\section{Conclusions}

AZO films were deposited with magnetron sputtering. The impact of Rapid Thermal Annealing was investigated in close connection with structural, optical and electronic properties. During annealing, two phenomena occur in different temperature ranges. Between 350 and $550{ }^{\circ} \mathrm{C}$, phase segregation occurs inside the layer, as assessed by the gap shift and the increase of visible luminescence. A kinetics study shows the relation between the intensity of visible luminescence and the shift of the gap. Above $800{ }^{\circ} \mathrm{C}$, there is an increase of the crystalline phase and grain size, as demonstrated by XRD and SEM. This increase leads to an overall increase of the luminescence and specifically of the UV peak. It is then possible to modify the PL spectrum of AZO thin films to obtain efficient white emission.

\section{Acknowledgements}

The authors thank Daniel Abriou for the SEM picture and Mohamed Selmane for assistance with XRD experiments. 


\section{References}

[1] F. Porter, Zinc Handbook: Properties, Processing, and Use in Design. CRC Press, 1991

[2] Y. Chen, D. M. Bagnall, H. J. Koh, K. T. Park, K. Hiraga, Z. Zhu, J. Appl. Phys. 84 (1998) 3912

[3] N. E. Hsu, W. K. Hung, Y. F. Chen, J. Appl. Phys 96 (2004) 4671-4673

[4] M. D. Mccluskey, S. J. Jokela, J. Appl. Phys. 106 (2009) 071101

[5] A. Che Mofor, A. El-shaer, A. Bakin, A. Waag, Appl. Phys. Lett. 87 (2005) 062501

[6] M. Joseph, H. Tabata, and T. Kawai, Appl. Phys. Lett. 74 (1999) 2534

[7] X. Jiang, F. L. Wong, M. K. Fung, and S. T. Lee, Appl. Phys. Lett. 83 (2003) 1875

[8] S. Müller, M. Lorenz, C. Czekalla, G. Benndorf, H. Hochmuth, M. Grundmann, H. Schmidt, C. Ronning, J. Appl. Phys.104 (2008) 123504

[9] N. Ohashi, T. Nakata, T. Sekiguchi, H. Hosono, M. Mizuguchi, T. Tsurumi, J. Tanaka, H. Haneda, Jpn. J. Appl. Phys. 38 (1999) L113.

[10] M. Wang, E. Woo, S. Jin, S. Chung, K. Koo, J. Mater. Sci. 45 (2010) 4111

[11] N. Ohashi, N. Ebisawa, T. Sekiguchi, I. Sakaguchi, Y. Wada, Appl. Phys. Lett. 86 (2005) 091902

[12] S. Kuo, W. Chen, F. Lai, C. Cheng, H. Kuo, S. Wang, W. Hsieh, J. Cryst. Growth 287 (2006) 78

[13] Y. Sobajima, S. Kato, T. Matsuura, T. Toyama, H. Okamoto, J. Mater. Sci.: Mater Electron. 18 (2007) 159

[14] K. K. Kim, H. Tampo, J. O. Song, T. Y. Seong, S. J. Park, J. M. Lee, S. W. Kim, S. Fujita, S. Niki, Jpn. J. Appl. Phys. 44 (2005) 4776

[15] M. Cui, X. Wu, L. Zhuge, Y. Meng, Vacuum 81 (2007) 899

[16] G. Fang, D. Li, B. Yao, Thin Solid Films 418 (2002) 156

[17] M. Wang, K. E. Lee, S. H. Hahn, E. J. Kim, S. Kim, J. S. Chung, E.W. Shin, C. Park, Mater. Lett. 61 (2007) 1118

[18] Y.J. Lin, W. C. Chen, H. C. Chang, C. J. Liu, Z.R. Lin, J Cryst. Growth 310 (2008) 4110

[19] J. H. Noh, H. S. Jung, J. K. Lee, J. Y. Kim, C. M. Cho, J. S. An, K. S. Hong, J. Appl. Phys 104 (2008) 073706 
[20] S. Hu, Y. Lee, J. Lee, J. Huang, J. Shen, W. Water, Appl. Surf. Sci. 254 (2008) 1578

[21] Y. Zhou, P. J. Kelly, A. Postill, O. Abu-Zeid, A. A. Alnajjar, Thin Solid Films 447 (2004) 33

[22] S. T. Tan, X. W. Sun, X. H. Zhang, S. J. Chua, B. J. Chen, C. C. Teo, Jpn. J. Appl. Phys. 100 (2006) 033502

[23] Joint Comitee on Powder Diffraction Standards, Powder Diffraction File 036-1451

[24] F. Conchon, P.O. Renault, P. Goudeau, E. Le Bourhis, E. Sondergard, E. Barthel, S. Grachev, E. Gouardes, V. Rondeau, R. Gy, Thin Solid Films 518 (2010) 5237

[25] V. Hauk, Structural and Residual Stress Analysis by Nondestructive Methods, Elsevier, 1997

[26] H. P. Klug, L. E. Alexaander, X-ray diffraction procedure for crystalline and amorphous materials, Wiley, New York, 1974

[27] E. Ziegler, A. Heinrich, H. Oppermann, G. Stover, Phys. Stat. Sol. A 66 (1981) 635

[28] G H Lee, Y Yamamoto, M Kourogi, M Ohtsu, Thin Solid Films 386 (2001) 117-120

[29] S. Cornelius, M. Vinnichenko, N. Shevchenko, A Rogozin, A Kolitsch, W. Möller, Appl. Phys. Lett. 94 (2009) 042103.

[30] S. Yoshioka, F. Oba, R. Huang, I. Tanaka, T. Mizoguchi, T. Yamamoto, J. Appl. Phys. 103 (2008) 014309.

[31] S. Cornelius, M. Vinnichenko, N. Shevchenko, a Rogozin, a Kolitsch, W. Möller, Applied Physics Letters 94 (2009) 042103

[32] M. Lorenz, R. Johne, T. Nobis, H. Hochmuth, J. Lenzner, M. Grundmann, A.P.D.

Schenk, S.I. Borenstain, A. Schön, C. Bekeny, T. Voss, and J. Gutowski, Appl. Phys. Lett. 89 (2006) 243510

[33] C Chandrinou, N Boukos, C Stogios, and A Travlos, Microelectronics Journal 40 (2009) 296-298

[34] W. D. Wright, The Measurement of Colour, 4th ed., Adam Hilger, London, 1969 


\section{Figure captions}
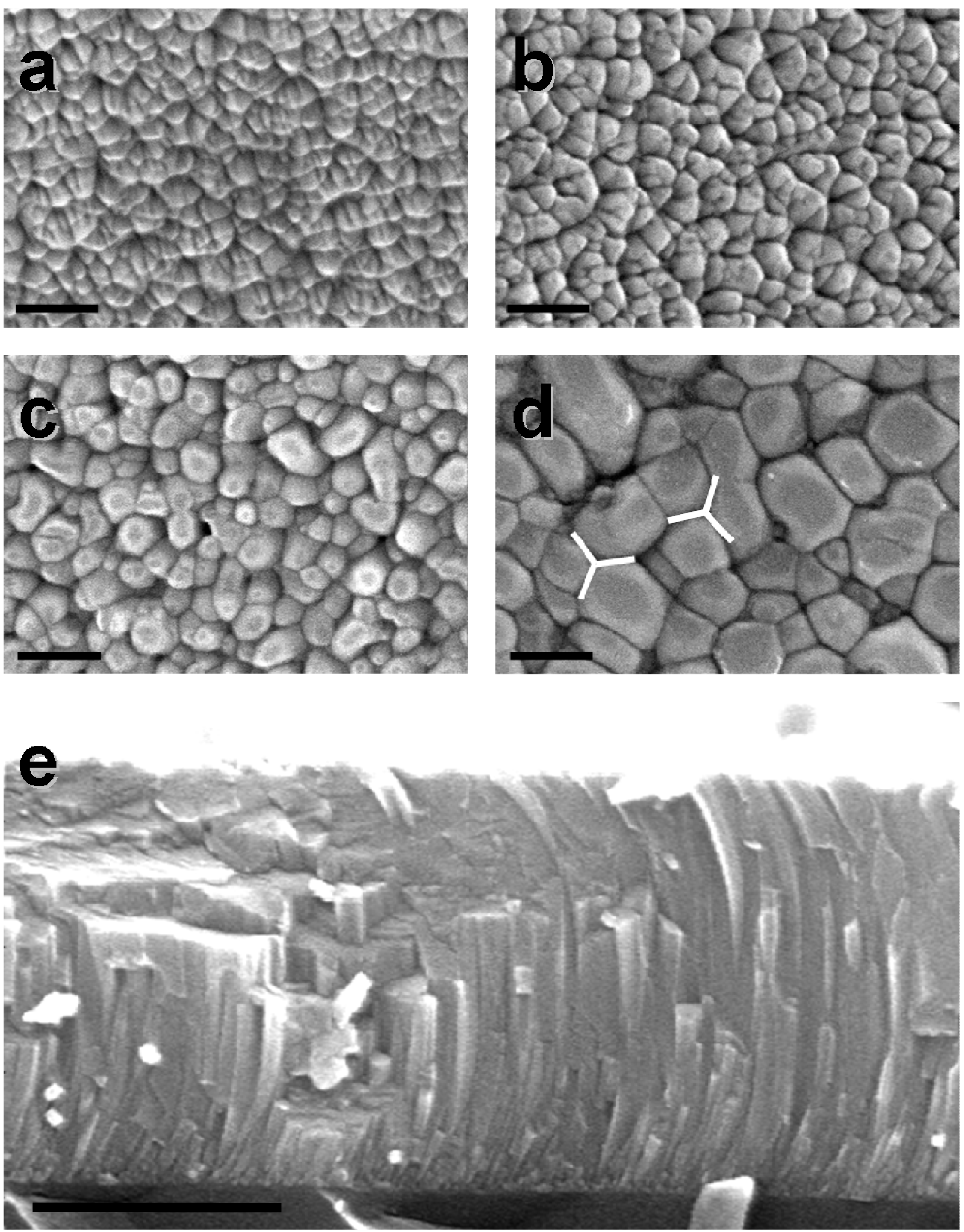

FIG. 1. SEM images of AZO thin films. a-d: top view of the surface before (a) and after annealing during $300 \mathrm{~s}$ at $\mathrm{T}_{\mathrm{a}}=650{ }^{\circ} \mathrm{C}(\mathrm{b}), 800{ }^{\circ} \mathrm{C}(\mathrm{c})$, and $900{ }^{\circ} \mathrm{C}(\mathrm{d})$. The scale bar is $200 \mathrm{~nm}$. e: side view of the film. The scale bar is $500 \mathrm{~nm}$. 

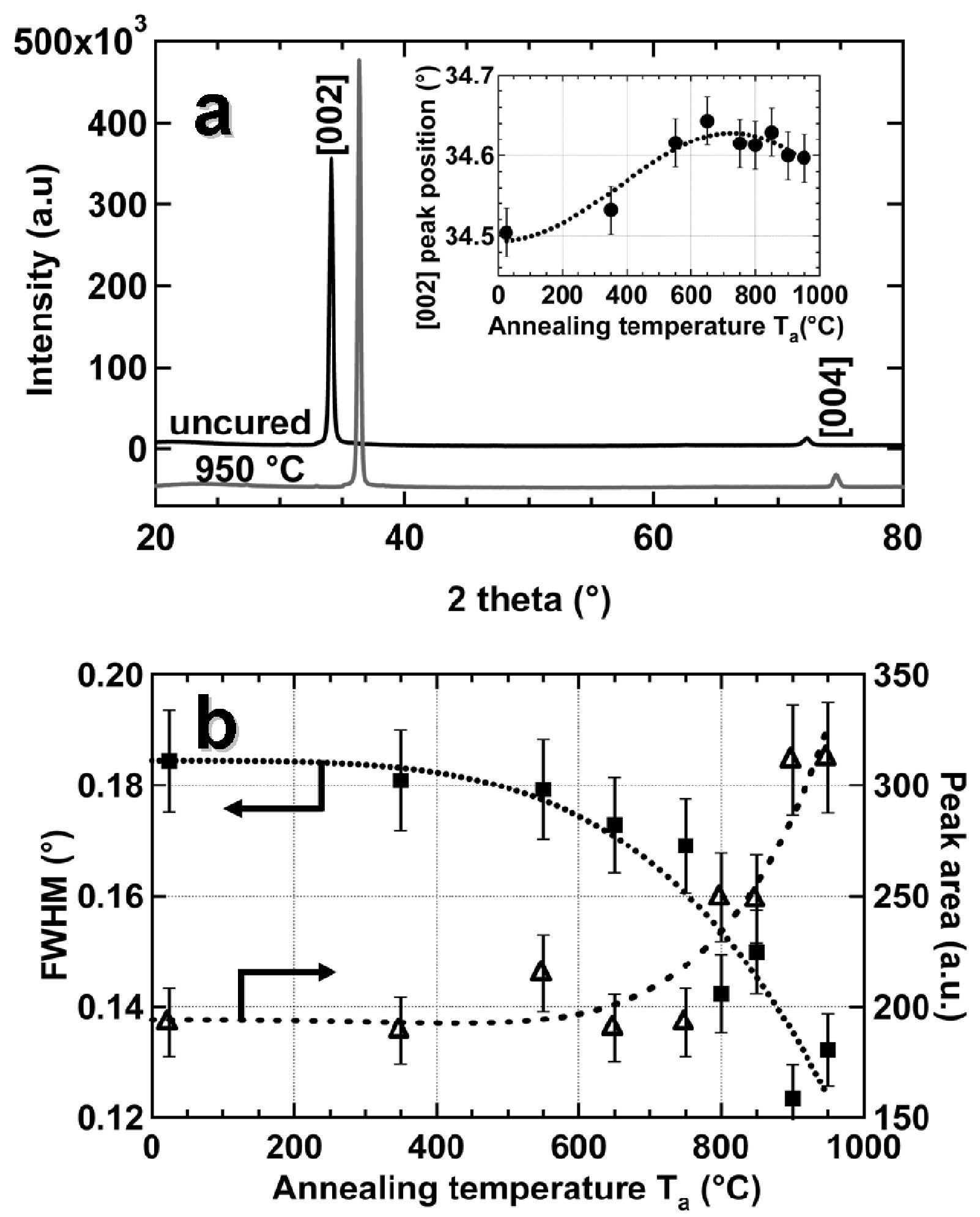

FIG. 2 (A) X-Ray Diffractogramm of AZO samples before and after annealing at $950^{\circ} \mathrm{C}$ for $300 \mathrm{~s}$. The curve at $950^{\circ} \mathrm{C}$ was right-shifted for clarity. Inset: [002] peak position after annealing at various temperatures for 300 s. (B) Full-width at half-maximum (square) and area (triangle) for the [002] peak. 


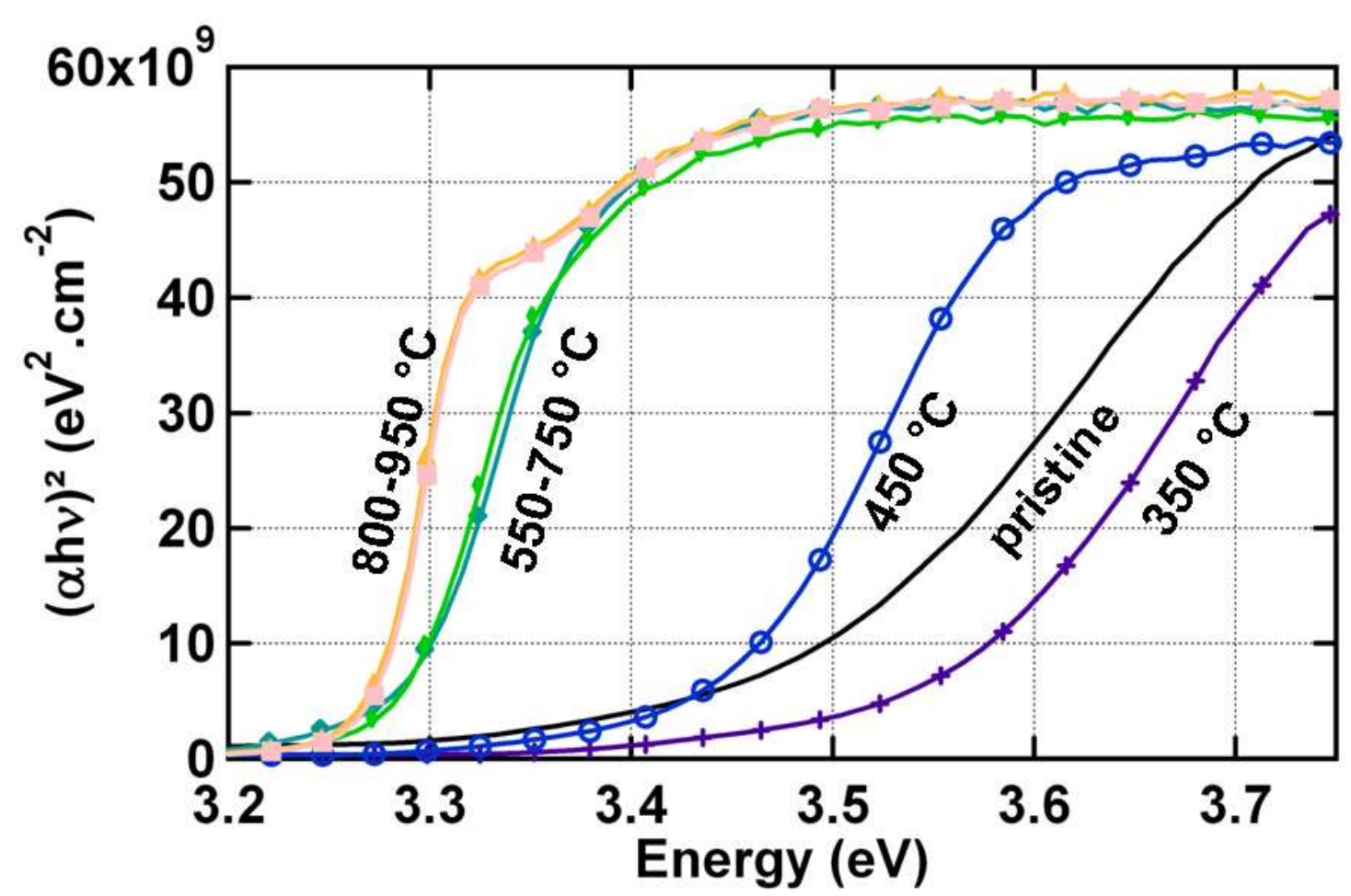

FIG. $3(\alpha h v)^{2}$ as a function of the photon energy $h v,(\alpha$ is the absorption coefficient) for AZO samples annealed under argon at various temperatures for $300 \mathrm{~s}$. The absorption coefficient was measured with a UV-Vis spectrophotometer.

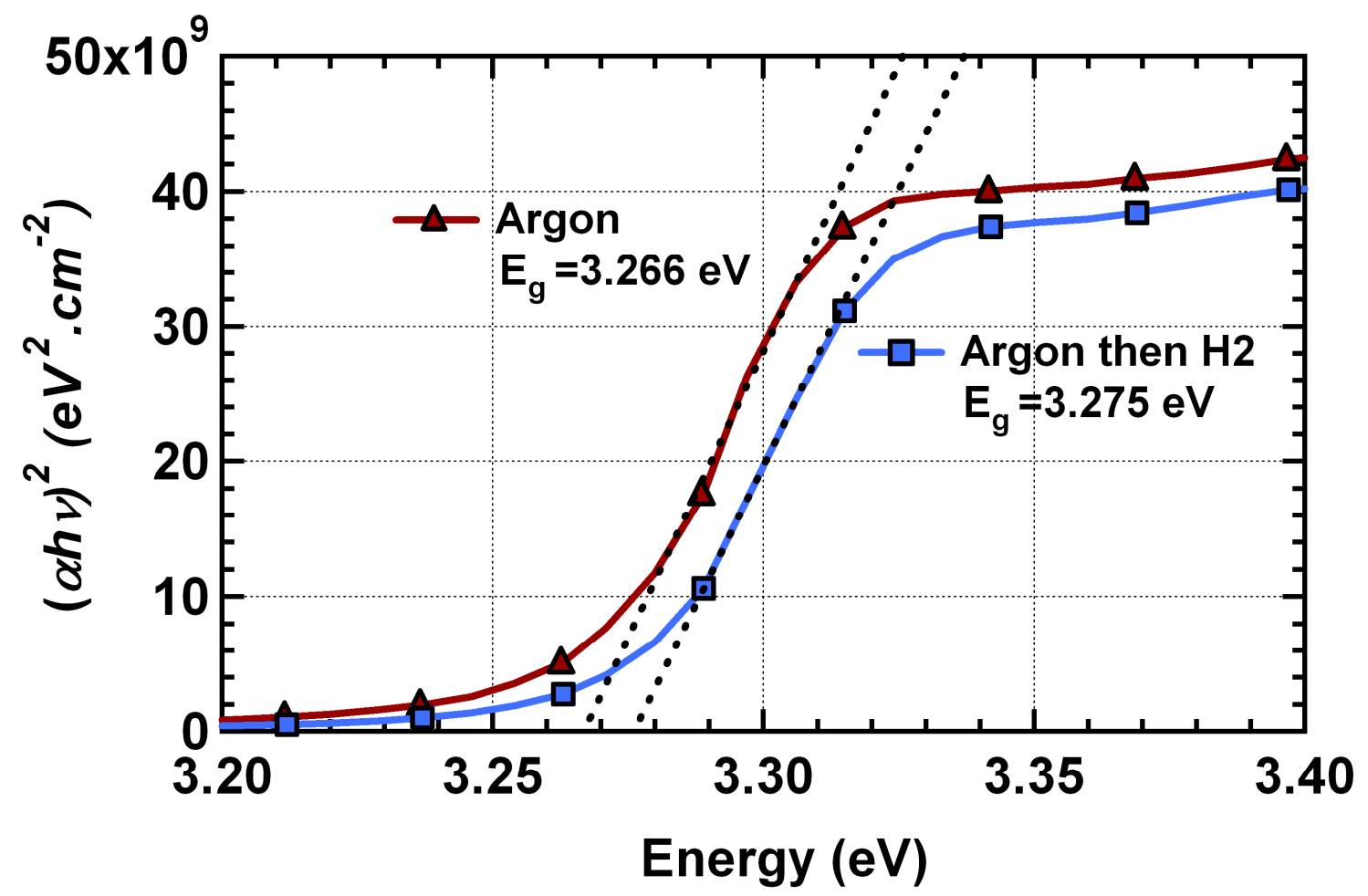

FIG. $4(\alpha h v)^{2}$ as a function of the photon energy hv, ( $\alpha$ is the absorption coefficient) for AZO samples annealed under argon at $950{ }^{\circ} \mathrm{C}$ for $300 \mathrm{~s}$ (red line), and subsequently annealed one hour at $450{ }^{\circ} \mathrm{C}$ under hydrogen (blue line). The absorption coefficient was measured with a $\mathrm{UV}$-Vis spectrophotometer. 

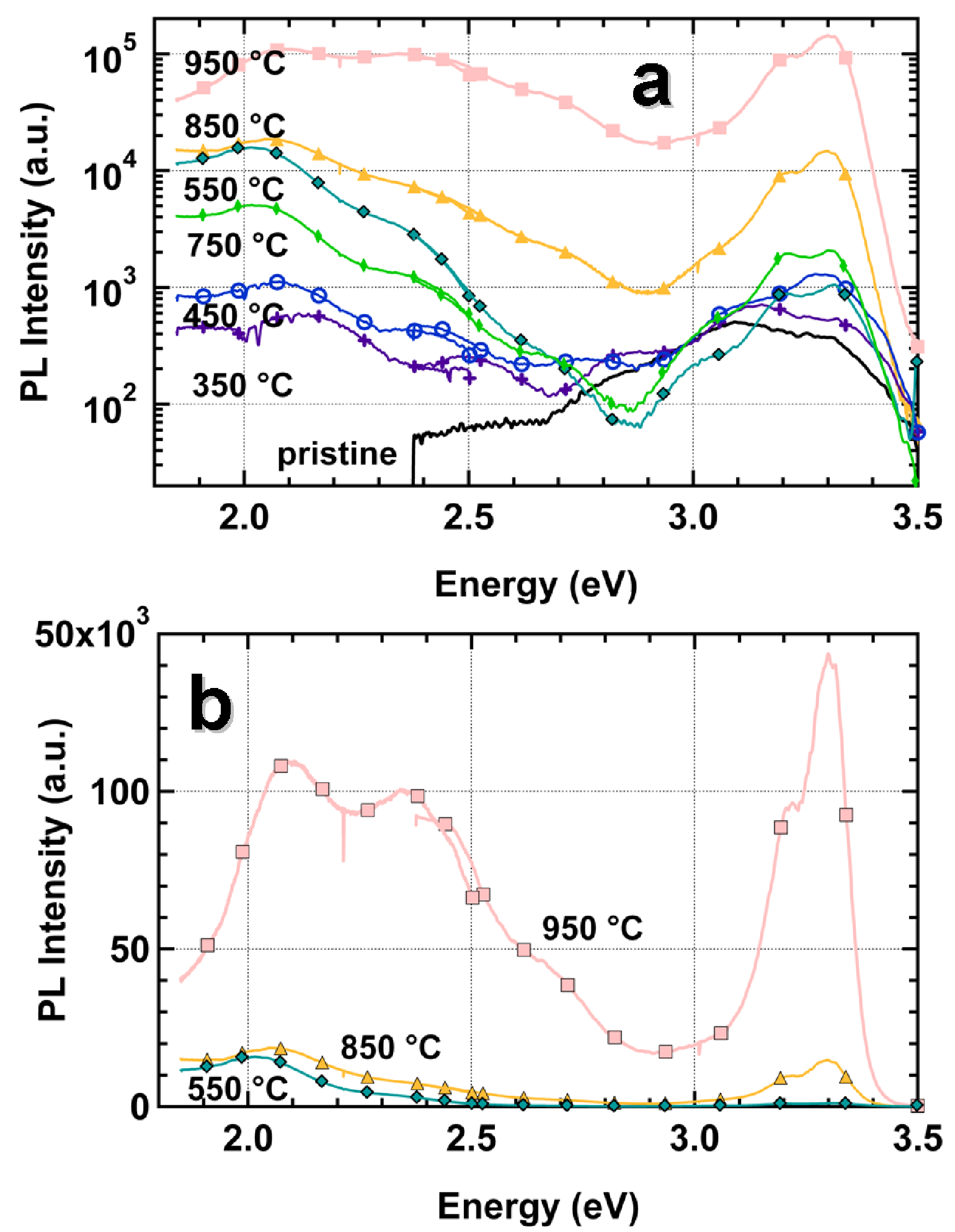

FIG. 5 Photoluminescence intensity as a function of the photon energy $h v$, for AZO samples annealed under argon at various temperatures for $300 \mathrm{~s}$, in a logarithmic (a) and linear (b) scales. The PL spectra were collected under normal incidence with an excitation energy of $3.8 \mathrm{eV}(325 \mathrm{~nm})$. 


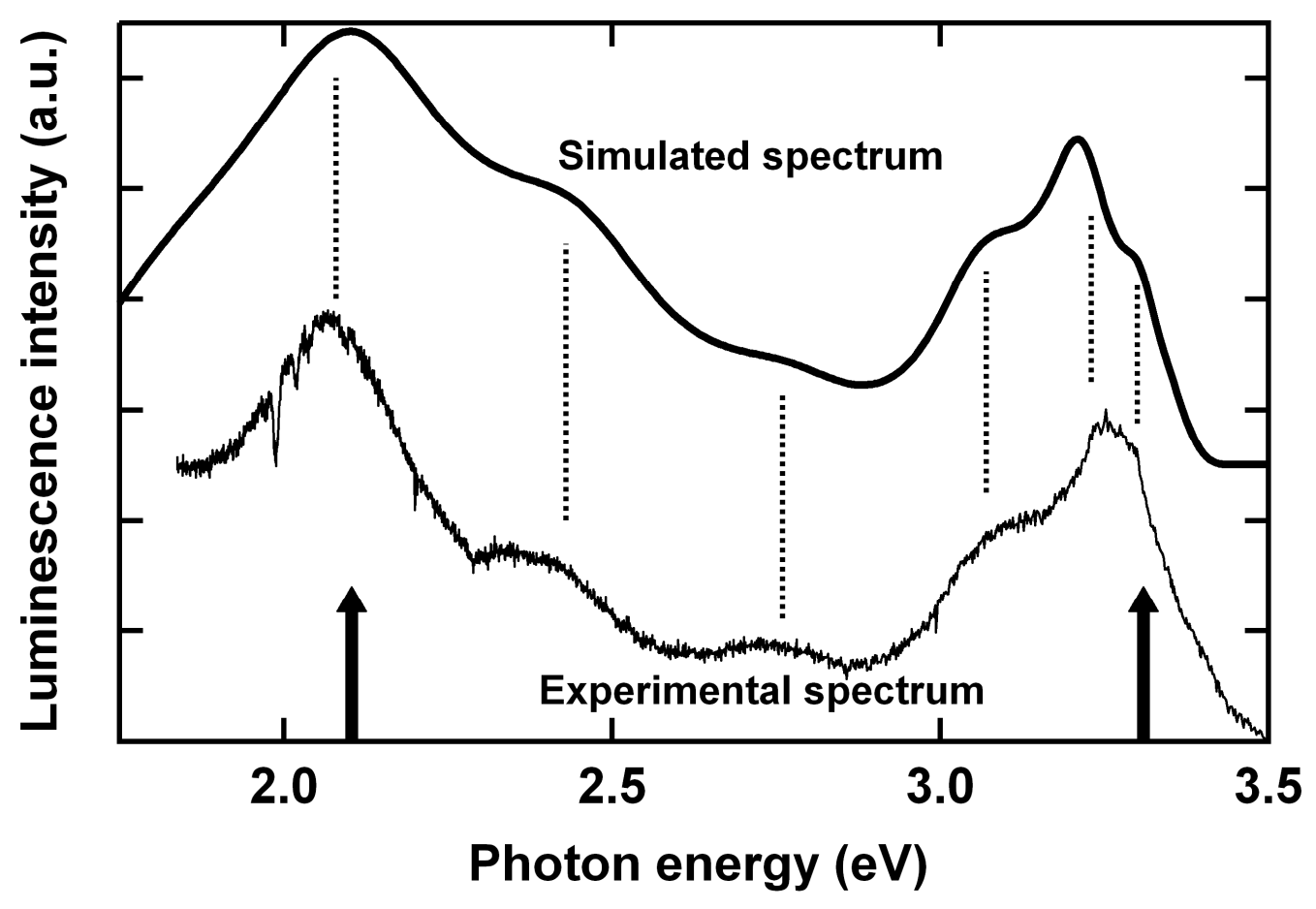

FIG. 6

Bottom: Experimental luminescence after annealing at $450{ }^{\circ} \mathrm{C}$. Top Simulated spectrum obtained from the sum of two Gaussian peaks (respective positions are indicated by the arrows) multiplied by the transmission. The dashed lines illustrate the coincidence of the local maxima.

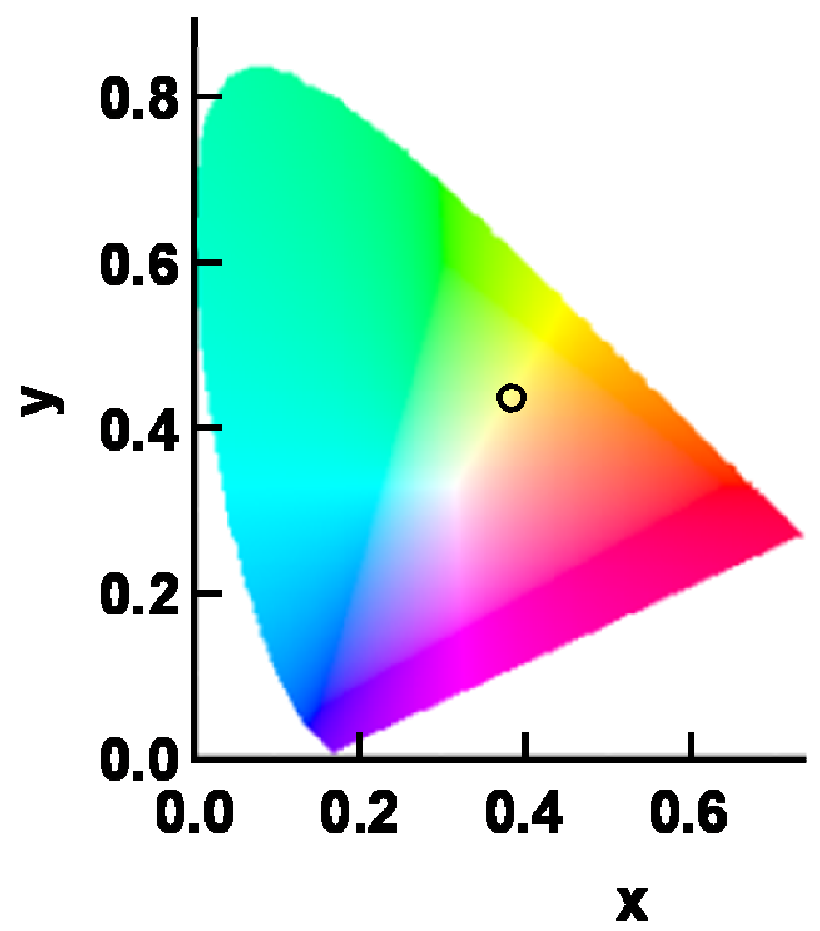

FIG. 7 Chromaticity of the emission of the AZO film annealed at $950{ }^{\circ} \mathrm{C}$ as reported in the color map defined with the CIE 1931 standards 


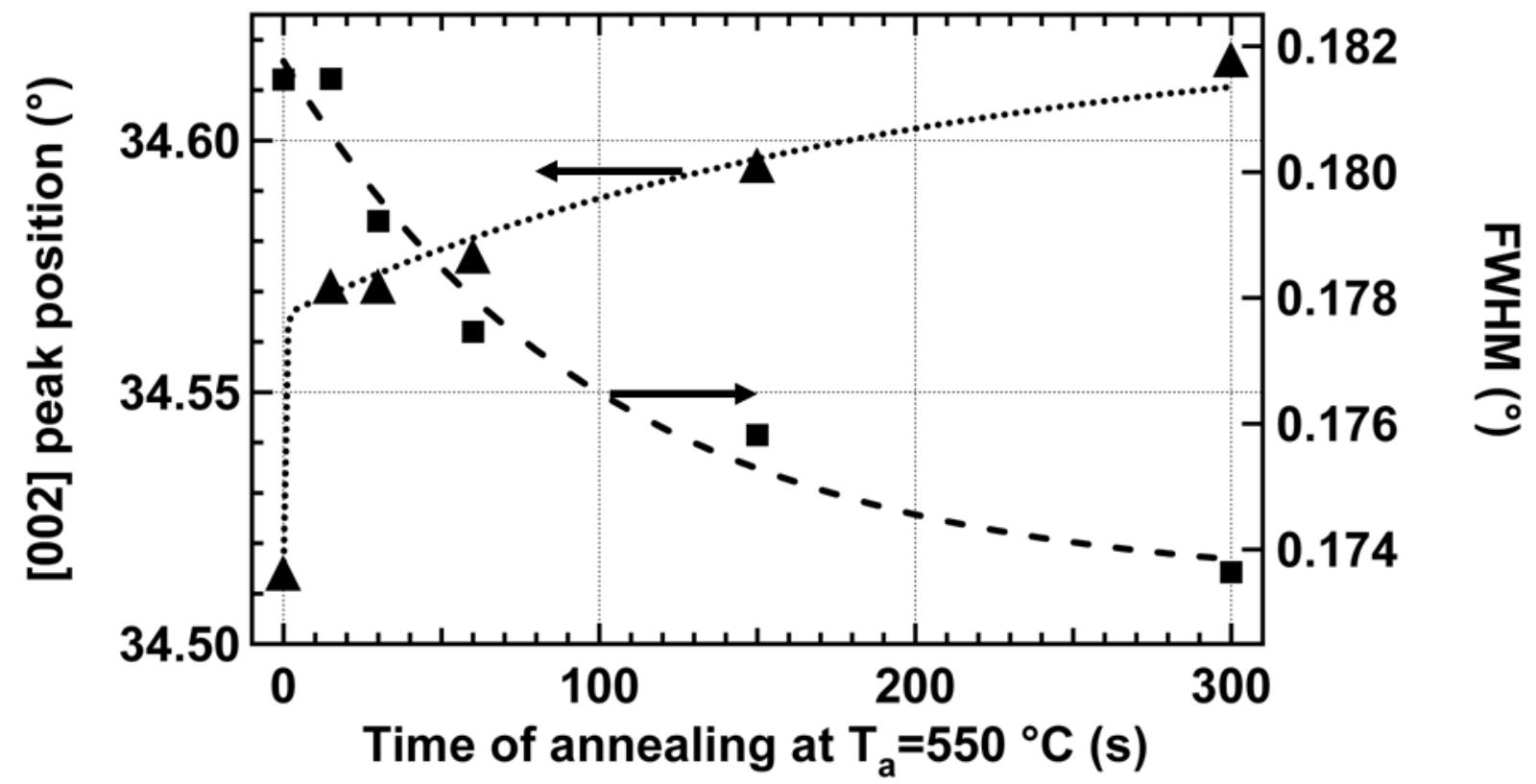

FIG. 8 X-Ray Diffraction experiments on AZO thin films before and after annealing at $550{ }^{\circ} \mathrm{C}$ for various time $t_{\mathrm{a}}$. Full-width at half-maximum (square) and position (triangle) for the [002] peak.
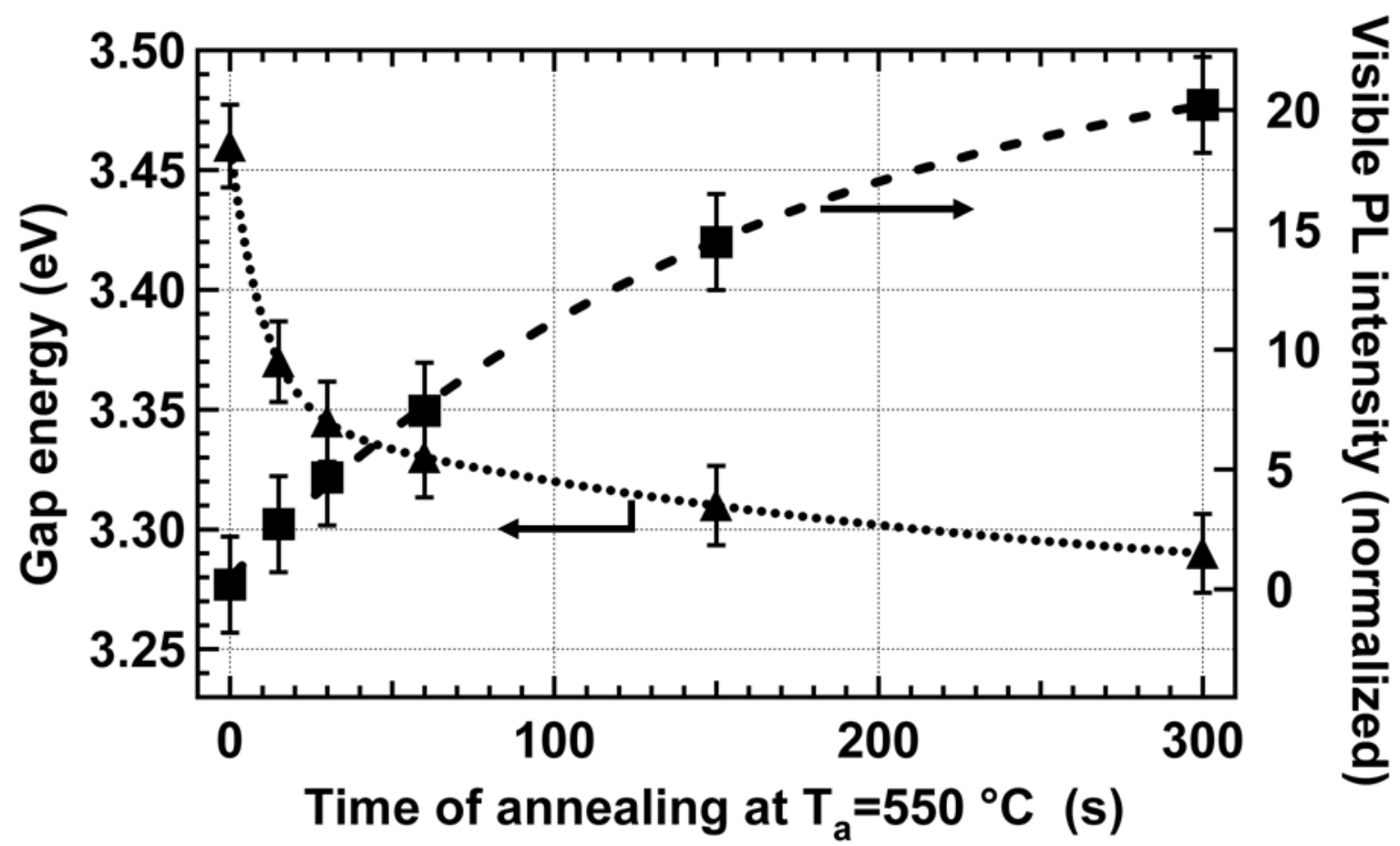

FIG. 9 AZO thin films annealed under argon at $550{ }^{\circ} \mathrm{C}$ for various annealing times. Optical gap energy (triangles) measured from the absorption coefficient and ratio between the visible and the UV peaks (square) in PL experiments as a function of the annealing time. 


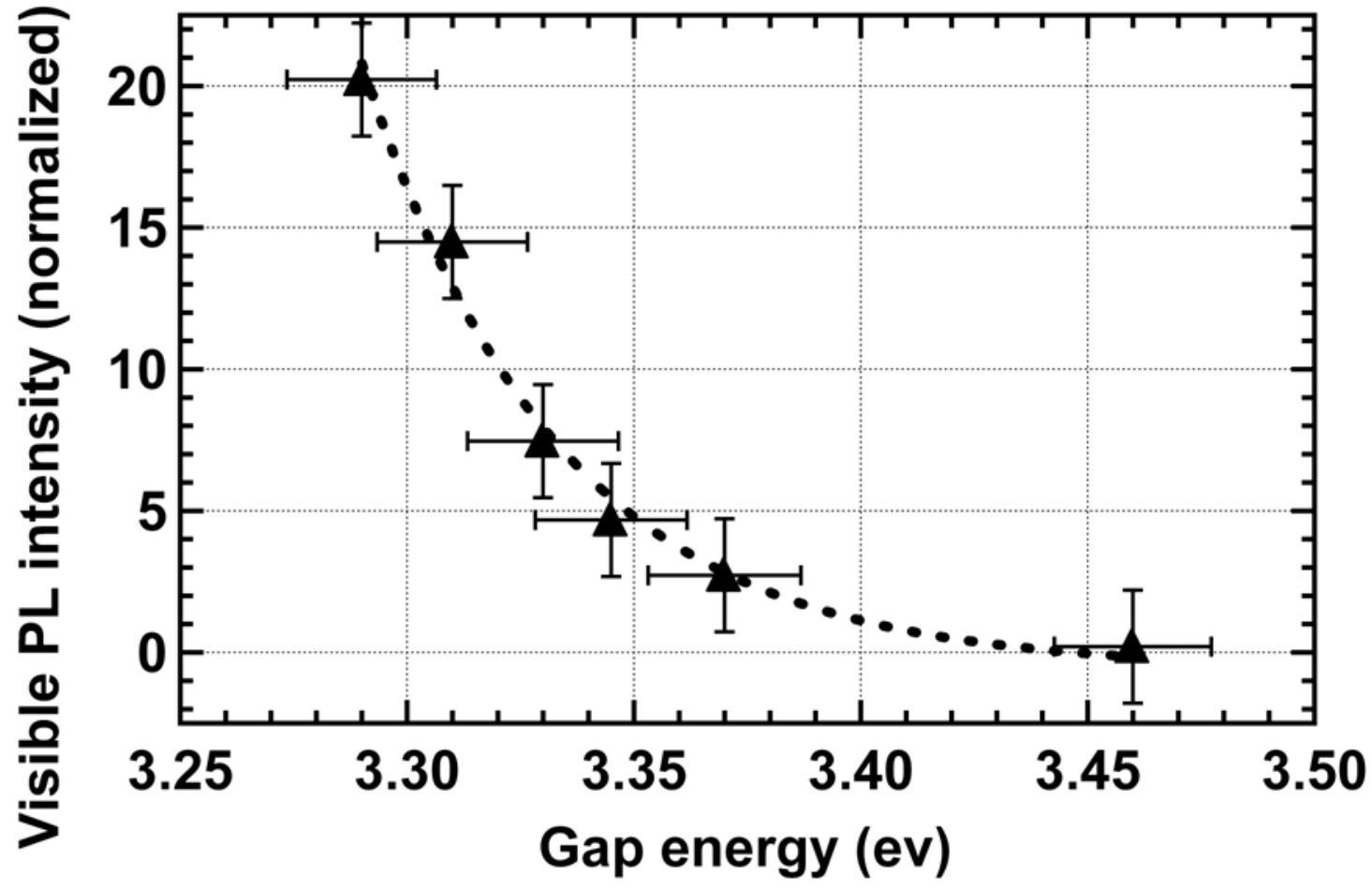

FIG. 10 AZO thin films annealed under argon at $550{ }^{\circ} \mathrm{C}$ for various annealing times. Optical gap energy as a function of the normalized visible PL intensity.. 